\title{
Changing Pattern of Hospitality Demand in Northern Nigeria
}

\author{
Matthew Apeh Adejoh PhD \\ Department of Hospitality and Tourism Management the Federal Polytechnic, Bauchi, Nigeria
}

\begin{abstract}
The hospitality demand pattern in the Northern Nigeria is assuming an interesting dimension in the recent times. The traditional apathy for eating out is giving way to an increasing demand for function catering which leaves unsatisfied demand especially during weekends and festive periods. This paper investigated the changing pattern of demand for the hospitality industry. A survey of randomly selected users from Sokoto, Kano and Bauchi towns, totalling 300 respondents revealed that the level of socialisation has broken the cultural barriers in demand for accommodation, food and drinks. A mean test analysis showed a strong preference for use of restaurants, banquet halls, canopies and recreational areas during weekends and festive periods such as Sallah and Christmas for reception and hosting of important events; 87\% of the respondents and their families personally engaged in one kind of functions or the other. The implication of this finding is that while many big hotels may experience low occupancies, those who are into outdoor catering may be faced with pressures of trying to cope with demand. It is therefore recommended that hospitality investors in Northern Nigeria should shift emphasis from building the so called 'big hotels' to exploring the fallow or vacant demand ground for function catering
\end{abstract}

Keywords: Hospitality demand Hotel and Catering supply Function catering

\section{Introduction}

Despite the immense contributions of the hospitality industry to national economy in terms of employment generation and general quality of life [1], the demand for its services suffered low returns in Northern Nigeria in past years [2]. This position was informed by the adherence to religious tenets which looked at those using hotel and catering services as infidels and worthless individuals According to [3], the local residents' attitudes greatly affect the demand for hospitality products. A devout believer and / or a responsible person was supposed to sleep and eat at home with members of his family all the times. This position which gave the hospitality industry a 'taboo' image in Muslim dominated Northern Nigeria obtained until recently when a new wave of demand emerged. As [13] forecasted, there is a better and brighter future for the hospitality industry. The landscape is evolving quickly as new technology demands that hotels become more social and engaging in their marketing efforts, travellers are looking for the best value propositions, and consumer demand is pushing for hotels to make concerted efforts on property upgrades and improvements. As the economy is growing so is the demand for excellent hotel services in the secondary cities where more business people are now visiting. According to [4], the economy is forecast to grow at a rate of $6 \%$ over the coming years. The positive economic growth prospects and the expected expansion of the agriculture sector would make the outlook for the hospitality sector extremely good.

\subsection{Hospitality Demand}

The willingness and ability of consumers to fulfil their needs constitutes the demand for those goods and services. The buyers and sellers constitute the demand and supply sectors [5]. The hospitality demand is synonymous with tourism demand because hospitality is regarded as a tourism hardware or resource. In tourism, the concept of demand may be extended to cover individuals' needs for consuming and experiencing places. Tourists buy souvenirs and clothes and use services such as accommodation, food and beverages and amusement parks

Tourism demand is the total of people participating in tourism activities, presented as the number of arrivals or departures, amount of money spent or other statistics [6]. People have a demand for goods, services and places that are marketed as individual products and product packages. The desire for any goods and services relates to changes in the demand and supply sectors, and their interaction. As to hospitality buyers, they easily react to an increase or decrease in their personal disposable income and its distribution, time budgets and other personal motives. There may also be more general changes in the demand generating area, such as economic depression and political uncertainty. Changes among the sellers instead refer to variations in the price level compared to rival destinations, business environment, transportation connections and product assortment, among other factors. The contact between the buyers and sellers is sensitive to promotion, attainability and marketing. 
Tourism demand, otherwise known as hospitality demand, may be categorised according to the willingness and ability of patrons to participate in tourism activities. Reference [7] distinguish among different types of hospitality and tourism demand. Effective demand (also called actual or aggregate demand) consists of people who actually take part in tourism activities (that is, the buyers collectively). The size of this group of buyers is the easiest to measure as they, having physically moved to the site of activities, are traceable. Latent demand (also called suppressed demand) refers to would-be buyers. This type consists of the deferred and potential demand. Deferred demand refers to those who have the will to participate in tourism activities but cannot, as they lack supporting knowledge or an access to tourism facilities, or both. The passivity of this type is due to the inefficiency of the supply sector to provide and market their products. Potential demand consists of those who have the will to participate but lack supporting social and economic circumstances. In other words, they do not have enough money or other resources to accomplish their plans. Their participation would require an improvement in their socioeconomic environment. Finally, people showing no demand have neither the will nor possibilities to participate in tourism activities.

Reference [8] identifies three categories of primary hospitality demand segments: commercial, meeting and group, and leisure. It is up to an operator to determine or establish what kind of patrons he seeks to attract and what demand base he needs to target. Is it Corporate and government representatives on long-term business? Leisure travellers? Families? Or Larger groups? Identifying the market segmentation, or the percentage breakdown of demand "types" for an area, is vital in answering these questions Each market segment exhibits unique characteristics relating to future growth potential, seasonal aspects of demand, average length of stay, rates of double occupancy, facility requirements, price sensitivity, and other factors [8]. Thus, knowledge of market segmentation gives investors and developers a means of gauging the profit potential for a hotel and catering enterprise, as well as avoiding costly mistakes by building a property aimed at capturing demand that the market does not supply. Once the concentration levels of primary demand segments in a market is determined, the decision as to what type of hotel facility is best suited to capturing that demand becomes much clearer

In his contributions, [8] describes the characteristics of the three primary segments. The commercial segment consists of individuals who travel to a market to conduct business. Not surprisingly, commercial demand tends to be heavy from Monday through Thursday, congruent with the business hours of local firms, and fall sharply through the weekend. Corporate groups and those in social, military, ethnic, religious, fraternal, and educational category make up the bulk of meeting and group demand, which consists of seminars, conventions, trade association shows, and similar gatherings of ten or more people. Demand in this segment is highest in the spring and fall, with activity slowing in the summer months. The consumers in this segment typically prefer hotels with extensive meeting space, business technology, food and beverage outlets, and the miscellaneous components required to host meetings and banquets. Unlike the weekday prominence of commercial and meeting and group demand, the leisure market segment tends to fill rooms and halls on Friday and Saturday nights. Leisure demand in markets is primarily generated by attractions such as amusement parks, shopping malls, outlet stores, and museums [9]. Events such as college graduation ceremonies or visits among families and friends also provide incentive for leisure travel in a market .It is this last category that dominates the hospitality market in Sokoto, Kano and Bauchi. Basically, the sellers (operators) usually witness the upsurge of demand arising from ceremonies such as weddings, birthdays, meetings, memorials, and sports activities. Congestion at parks, reception halls, gardens, restaurants, school premises, and temporary tents and canopies is noticeable.

Reference [10] links hospitality development to Otus theory of hotel demand and supply designed to make sense of developments in the size and structure of the hotel business and its medium to long-term prospects. The theory predicts that within an economy, the greater the contribution of service businesses to gross domestic product (GDP) then the greater the domestic business demand for hotels, the greater the domestic leisure demand for hotels, the greater the supply of hotels, the greater the concentration of hotels in brands and the greater the diversity of branded hotels. The theory examines the relationships between economic structure, hotel demand and hotel supply. The volume of demand for and the extent of supply of, the hospitality products and services depend on some economic variables which determine the propensity or level of participation in the market. Analysing the socio - economic determinants of tourism demand, Reference [11] outlined the motivation for participation in tourism activities to include desire for play, pleasure, shopping, recreation, relaxation, social interaction, prestige, wish fulfilment and family bonding. The level of participation is dictated by the level of income, price structure and availability of time. Reactions of demand to economic changes are expressed as elasticities. The income elasticity of demand compares the percentage change in quantity demanded in relation to an equal change in disposable income

To maintain a stable profitable market, it is necessary to engage in hospitality demand management. Hospitality demand management is defined by [12] as the art and science of dynamically managing demand for hospitality services to optimize profitability and customer relationships. It relies on, and goes beyond, 
traditional applications of pricing, revenue management, marketing and channel distribution to manage near and long term demand from key customer segments. It assesses the current trends in hospitality service demand from the leisure, business and group segments plus a set of principles for managing and balancing demand from each of the segments. This is done in the context of an evolving distribution environment where distribution and marketing is increasingly moving online and to mobile devices.

\section{Research Methodology}

A total of three hundred users, comprising $120(40 \%)$ service providers and $180(60 \%)$ consumers of the hospitality services was randomly selected from three main Northern Nigerian cities of Sokoto, Kano and Bauchi . The survey was conducted between October 2011 and September 2012. Apart from occasional visits, at least three weekends were spent at each of the three cities to provide opportunities for close supervision of questionnaire administration and conduct of interviews. Interpreters were used to elucidate difficult words between the researcher and the respondents. There was a reasonable spread in sourcing for data as both major and minor hospitality outfits within the cities were reached, including hotels, restaurants, amusement parks, reception centres, gardens, school premises used as reception grounds, and canopy renters. The study was majorly conducted at weekends when demand and supply were at the peak

A 10-item structured questionnaire used for the survey addressed such issues as demographics, frequency of usage of hospitality services, determining factors for consumers 'behaviour, occupancy levels, and probable growth potentials of the market. Five each of operators/managers and customers were interviewed at each study area to augment data supplied through questionnaire. Data were analysed by descriptive statistics. Mean distribution and standard deviation were calculated for frequency of use by patrons, occupancies, determinants of demand, factors influencing customers' behaviour and estimated growth potentials, based on 6point scale for frequency of usage and 5-point Likert scale for demand determinants.

\section{Results And Discussions}

The respondents $(n=300)$ were asked to indicate their organizational position classifications within three discrete categories that included: Worker, Owner, Customer. The majority of respondents were customers $(61.67 \%)$ and workers $(33.33 \%)$. Five percent of respondents were owners of enterprises. Sixty-two percent of respondents were male and 38\% were females. Forty percent of respondents had $6-10$ years industry experience, $24 \%$ having over ten years exposure in the industry and $88 \%$ of them were within annual income bracket of below N1 million The demographic composition of the sampled population gave credence to the validity and reliability of data collected (See Table 1). Moreso, the income structure shows a distinct market segment that could be catered for.

Respondents were asked to comment on how frequently they availed themselves of hotel and catering services in order to determine the extent of hospitality demand. A plausible proportion (56.67\%) responded positively to this question that they used hospitality services more frequently. The mean average for this frequency was 4.64 with a standard deviation of 0.99 . Respondents were asked to report which industry's functional area or niche representation they were frequently or otherwise engaged in and they interestingly reported food service $(6.5 \pm 0.62)$ and outdoor catering $(5.49 \pm 0.84)$ as the most frequently patronized aspects of the industry. Table 2 (b) depicts a representation of this growing pattern of hospitality demand as predicted by [12]

\subsection{Determinants of Hospitality Demand}

This section of the questionnaire surveyed the respondents' opinions concerning the factors that boost demand for function catering in Northern Nigeria. Respondents were provided with a list of variables and they were required to indicate their level of agreement on a scale ranging from Strongly agree to Strongly disagree. Almost all, except graduation, were agreed to be contributory to the rising pattern of hospitality demand, most especially wedding reception, naming ceremonies and seminars The mean deviation for wedding, naming and seminars were $4.6 \pm 0.67,4.03 \pm 1.34$ and $4.4 \pm 1.05$ receptively Sixty-eight percent of respondents strongly agreed that wedding functions were contributing to the growing hospitality demand and supply while $63 \%$ agreed to seminars as a key factor. Table 3 provides a listing of responses to this section of the questionnaire. Among factors influencing the pattern of customer demand, income (4.65 \pm 0.52$)$ and environmental safety (4.7 $\pm 0.59)$ were strongly agreed to cause demand elasticities. This coincides with the opinion of Ryan (2003) who emphasized the role of income and price, among other factors, in tourism buying decision. The improvement in the socio-economic quality of life of people occasioned by new minimum wage, bumper harvest and increasing literacy level has paved way for changes in taste and desire for hospitality services which were hitherto regarded as a "taboo" and "out of reach" [9]

Table 5 shows the occupancy levels for different services offered by the industry during the period of the study. Practitioner respondents $(n=120)$ reported that while average weekly room occupancy stood at 38. 
$83 \%$ with a standard deviation of $25.91 \%$, the occupancy levels for restaurants, banquet halls and reception gardens averaged $52.58 \pm 29.91,59.67 \pm 28.24$ and $48.42 \pm 24.38$ respectively. This development aligns with Rauch's [13] prediction for better and brighter future for the hospitality industry, even in developing country like Nigeria, and particularly in Northern Nigeria. This explains the rush for, and congestion at, major outdoor catering facilities within the cities.

\subsection{Prospects of the Hospitality Industry}

All the respondents were positive about the prospect of the hospitality business in Northern Nigeria. At least, about $60 \%$ of respondents $(5.17 \pm 0.94)$ strongly agreed that the industry was much more likely to excel in the near future.[ See Table 6]. This would be made possible by growing awareness among natives on the relevance of the industry to the social well being of the people. Reference [14] noted that a complete understanding between people and the hotel is essential as that would readily portray the good perception of the industry. For better understanding, the practitioners will have to maintain the right relationship whilst at the same time ensuring sanity around the industry. In his contribution, [15] opined that dramatically, the hospitality industry would be growing as residents are becoming more positive and support the existence of the industry

\section{Conclusion}

The practitioners who responded to the survey instrument represented a wide range of hospitality and tourism industry sectors, with strongest concentrations in the lodging and foodservice categories. Other respondents indicated a deep sense of satisfaction with the industry which is evident in a large percentage of individuals who patronise food service and outdoor catering regularly. The implication of this is for the practitioners to explore the growing fertile ground for the industry and plough it profitably.

Thorough knowledge of demand segments helps establish bearings as a hotelier. The factors and trends that chart the past and help forecast future dynamics of these segments in Northern Nigeria are complex, but essential in determining the suitability of the improvements and amenities for proposed investments and in projecting future hotel usage. It is necessary to carry out demand segment analysis in order to be able to venture into profitable hotel business. Function catering holds promise for the industry in the future to come, judging from the current positive perception among the urban dwellers.

\section{References}

[1] WTTC (2006), World Travel and Tourism, Climbing to New Heights, London, available at: http://www.wttc.org.

[2] J Anstu, Challenges of marketing hospitality services in Northern Nigeria, .Postgraduate Diploma project. NIHOTOUR Bauchi, 2007

[3] Mansfeld, Y., \& Ginosar, O. (1994). Determinants of locals' perceptions and attitudestowards tourism development in their locality. Geoforum, 25, 227-248

[4] Page, V. (2012) 'Opportunities in Nigeria's hospitality and retail sectors'. Frontier Market Intelligence. Tradeinvest Nigeria, 19 Jan 2012

[5] Faulkner, B. and Valerio, P. (1995) 'An integrative approach to tourism demand forecasting', Tourism Management 16(1): 29-37.

[6] Crouch, G. I. (1994a) 'The study of international tourism demand: a survey of practice', Journal of Travel Research Spring: $41-55$. (Presents an overview of empirical studies on international tourism demand over three decades.)

[7] C Cooper, J fletcher and S Wanhill, The future of tourism (Eds.), Tourism: Principles and Practice, Pitman Publishing, London (1993), pp. 265-277

[8] Bisema, B. F. (2009). Hotel Demand Segmentation 101: Identifying Demand Segments and Understanding How They Relate to Property Performance Available http:/www.hus.com/Personnel/530/Brian-Bisema/ .Retrieved 5/11/2012

[9] Butler, R. (2006). The future and the TALC. In R. Butler (Ed.), The tourism area lifecycle: Conceptual and theoretical issues, Vol. 2 (pp. 281-290). Clevedon: ChannelView Publications.

[10] Slattery, P., The Otus theory of hotel demand and supply, Int. J. Hospitality Manage. (2008),doi:10.1016/j.ijhm.2008.06.005

[11] Ryan, C (2003) Recreational Tourism: Demand and Impacts. Australia: Channel View Publications.

[12] Anderson, C. and Carroll, B. (2010). "Demand Management: Beyond Revenue Management," Journal of Pricing and Revenue Management, Vol. 6, 4 260-263.

[13] RauchR(2011).Top10hospitalityindustrytrendsfor2012.Hotelmarketing.http:/www.rategain.com/rezgain.html?STC=hotelmarketing. Retrieved 4/11/2012

[14] Mattila, A S (2001) "The effectiveness of service recovery in a multi-industry setting", Pennsylvannia, USA) : MCB UP Ltd

[15] Dowling, G. (1993), "Developing your company image into a corporate asset", Long Range Planning, Vol. 26 No. 2, pp. 101-9. Newsome, D, Moore, S A and Dowling, R K (1993) Natural Area Tourism: Ecology, Impacts, and Management. USA: Channel View PublicationsUSA 


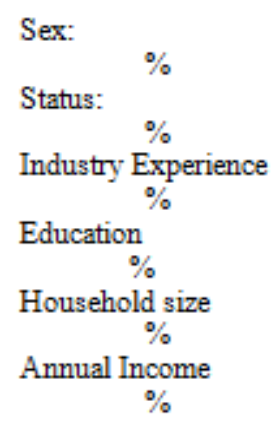

Table 1: Demographic Variables of the Respondents. $\mathrm{N}=\mathbf{3 0 0}$

$\begin{array}{lc}\text { Male } & \text { Female } \\ 186(62) & 114(38) \\ \text { Worker } & \text { Owner } \\ 100(33.33) & 15(5) \\ 1-5 \text { years } & \text { 6-10 years } \\ 109(36) & 121(40) \\ \text { Primary \& below } & \text { Secondary } \\ 97(32.33) & 118(39.33) \\ <5 & 5-10 \\ 20(6.67) & 210(70) \\ <\mathrm{N} 1 \mathrm{~m} & \mathrm{~N} 1-\mathrm{N} 5 \mathrm{~m} \\ 264(88) & 21(7)\end{array}$

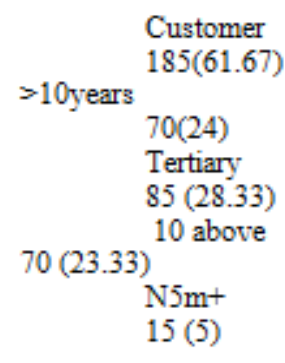

Table 2: Frequency of Usage of Hospitality Services. $\mathbf{n}=\mathbf{3 0 0}$

(a) How frequently hospitality services are demanded

$\begin{array}{lll}\text { Frequency of Usage } & \boldsymbol{f} & \text { Mean Deviation } \\ \text { Much more frequently } & 36 & \\ \text { More frequently } & 170 & \\ \text { Frequently } & 69 & \\ \text { Less frequently } & 5 & \\ \text { Seldomly } & 16 & \\ \text { Not at all } & 4 & \\ & 300 & 4.64 \pm 0.99\end{array}$

(b) How frequently industry niche is demanded

Industry Niche

Room

Food and beverage services

In-situ services

Outdoor catering

$$
6.5 \pm 0.62 \begin{aligned}
& \text { Mean Deviation } \\
& 3.43 \pm 1.52 \\
& 4.15 \pm 1.32 \\
& 5.49 \pm 0.84
\end{aligned}
$$

Table 3: Factors Determining Customer Demand

Determinants

Mean Deviation

$\mathbf{n}=\mathbf{3 0 0}$

Wedding reception

Birthdays

Naming ceremonies

$4.61=0.67$

$3.86 \pm 1.29$

Meetings

$4.03 \pm 1.34$

$3.81 \pm 1.15$

Family bonding interactions

$3.56 \pm 1.11$

Graduation

$3.18 \pm 1.22$

$4.4 \pm 1.05$

Conferences

$3.58 \pm 0.99$

Table 4: Factors Influencing Customer Behaviour

Influencing F actors
Income
Time
Price of services
Environmental Safety
Religion
Others

Services
Rooms
Restaurants
Banquet halls
Recreational gardens

Mean Deviation

$4.65 \pm 0.52$

$3.83=0.98$

$2.71=1.42$

$4.70=0.59$

$4.40 \pm 1.02$

$3.26 \pm 0.97$

Table 5: Average Weekly Occupancy Levels (\%) $\quad n=120$

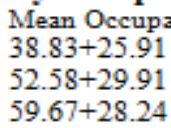

$52.58+29.91$

$9.67+28.24$

$48.42+24.38$

Table 6: Market Growth Potentials for Function Catering

Likely Growth Potential

Much more likely to be on the increase

f 143

Mean deviation

More likely to be on the increase

Likely to be on the increase

70

incely to be on the increase

Not likely to be on the increase

Not at all likely to be on the increase

5
1
2

$5.17+0.94$ 